\title{
PENGARUH CAUSE RELATED MARKETING DAN BRAND IMAGE TERHADAP BRAND TRUST PADA BIRO TRAVEL ONLINE
}

\author{
Surra Man Ra Ani \\ London School of Public Relations - Jakarta \\ Email: surramanraani@gmail.com
}

\begin{abstract}
ABSTRAK
Penggunaan media online yang semakin meningkat membuat biro travel beralih menjadi biro travel online dengan menggunakan media online sebagai media pemasaran. Salah satu biro travel online yang diteliti dalam penelitian ini adalah biro travel online ranijourney.com yang menggunakan cause related marketing sebagai metode pemasaran paket wisata yang ditawarkan. Tujuan dari penelitian untuk mengetahui pengaruh cause related marketing terhadap brand image dan brand trust pada biro travel online ranijourney.com. Teori yang digunakan adalah Social Judgement Theory dengan konsep Cause Related Marketing, Brand, Brand Image dan Brand Trust. Metode penelitian yang digunakan adalah metode kuantitatif dengan teknik analisis data regresi dan analisis jalur. Sampel dalam penelitian ini sebanyak 99 orang yang telah mengikuti program "Journey For The Hope" ranijourney.com tahun 2017. Hasil penelitian menunjukan terdapat pengaruh cause related marketing terhadap brand image, cause related marketing terhadap brand trust, brand image terhadap brand trust dan cause related marketing terhadap brand trust melalui brand image pada sebuah biro travel online.
\end{abstract}

Kata kunci: Travel online, cause related marketing, brand image, brand trust.

\begin{abstract}
The increasing use of online media has made travel agents turn to online travel agencies by using online media as a marketing tools. One of the online travel agency researched in this study is ranijourney.com that used cause related marketing as a method of marketing tour packages offered. The aim of the research was to determine the effect of cause related marketing and brand image on brand trust in online travel agency ranijourney.com. The theory used was Social Judgment Theory with the concept of Cause Related Marketing, Brand, Brand Image and Brand Trust. The research method used was quantitative method with regression data analysis and path analysis techniques. The sample in this study were 99 people who had attended ranijourney.com's "Journey For The Hope" program in 2017. The results showed that there was an effect of cause related marketing on brand image, cause related marketing on brand trust, brand image on brand trust and cause related marketing on brand trust through brand image in an online travel agency.
\end{abstract}

Keywords: Travel online, cause related marketing, brand image, brand trust.

\section{PENDAHULUAN}

Ajang kompetisi video pariwisata dunia yang digelar dalam $22^{\text {nd }}$ General Assembly UNWTO di Intercontinental Century City Convention Center Hotel, Chengdu, Tiongkok, dimana Indonesia menjuarai dua kategori sekaligus, sebagai Winner of UNWTO Video Competition 2017 Region East Asia and Pacific dan People's Choice Award 2017 menjadi bukti kemajuan pariwisata Indonesia yang didukung dengan peningkatan jumlah wisatawan mancanegara yang berkunjung ke Indonesia selama tahun 2015 sampai 2017.

Gambar 1 tentang grafik kunjungan wisatawan mancanegara ke Indonesia diatas menunjukan bahwa terdapat kenaikan yang cukup signifikan di tahun 2017. Jumlah wisatawan mancanegara tahun 2017 naik sebanyak lebih dari 13,8 juta kunjungan atau
20\% dibandingkan tahun 2016. Peningkatan jumlah pengunjung wisatawan mancanegara ini menjadi tolak ukur bagi pemerintah untuk terus mengembangkan destinasi wisata yang ada dengan didukung atas keberhasilan sektor pariwisata dalam menduduki posisi kedua terbesar sebagai penyumbang devisa negara sebesar US\$ 13,568 miliar di tahun 2016.

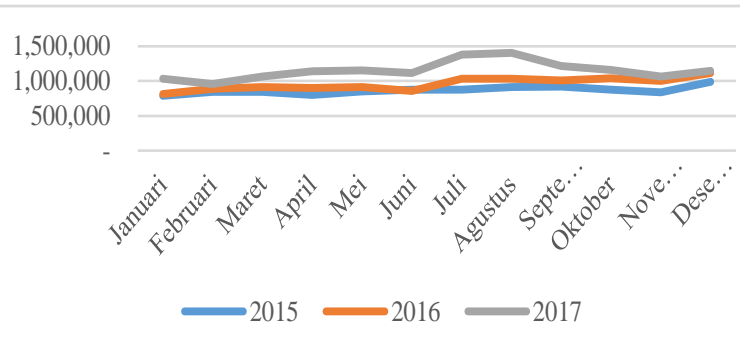

Sumber: http://kemenpar.go.id/image/contenttransaction/3504.jpg

Gambar 1. Grafik Kunjungan Bulanan Wisatawan Mancanegara 2015-2017 


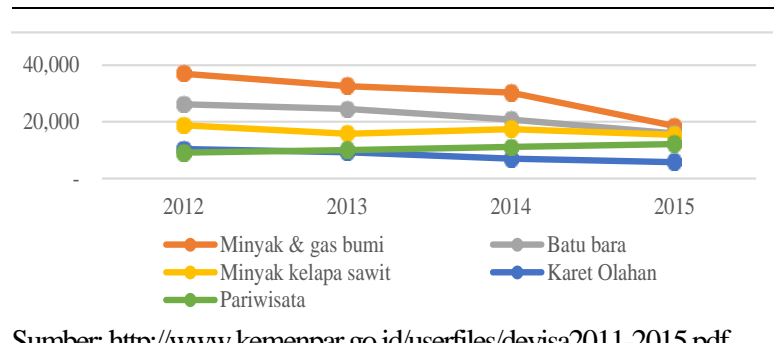

Sumber: http://www.kemenpar.go.id/userfiles/devisa2011-2015.pdf

Gambar 2. Grafik Devisa Pariwisata Terhadap 5 Ekspor Barang Terbesar 2012 - 2015

Gambaar 2 grafik devisa pariwisata menunjukan bahwa dari kelima sektor penyumbang devisa terbesar, hanya pariwisata yang mengalami kenaikan secara konstan di setiap tahunnya. Berbagai usaha pemerintah dalam mengembangkan pariwisata tentunya belum cukup tanpa peran dari pihak swasta, salah satunya biro travel yang memiliki peran sebagai jembatan antara wisatawan dengan masyarakat lokal yang berada di daerah tujuan wisata. Kondisi pariwisata saat ini yang sedang marak perhatian berbagai kalangan memiliki dampak baik dan buruk bagi biro travel. Selain memberikan peluang bagi biro travel untuk mengembang usaha yang dimilikinya, kondisi ini juga membuka kesempatan bagi pengusaha baru untuk mencoba peruntungan mereka dalam mendirikan biro travel sehingga arus persaingan semakin tinggi. Dalam menghadapi kondisi ini maka promosi menjadi salah satu aspek penting untuk digencarkan melalui berbagai media. Perkembangan teknologi yang ada saat ini nyatanya memberikan jawaban serta solusi bagi biro travel yang baru mengembangkan usahanya untuk melakukan promosi dengan biaya yang rendah, yaitu melalui media online. Media online juga memberikan peluang bagi biro travel untuk mempromosikan paket wisata mereka secara luas tanpa terbatas jarak dan waktu. Pengguna media online semakin menunjukan peningkatan yang cukup signifikan sehingga media ini merupakan media yang efektif dalam menjangkau pasar yang luas

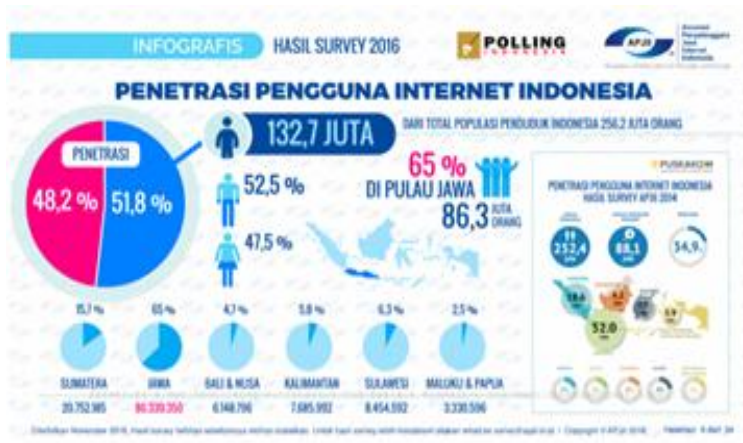

Sumber: Survei Asosiasi Penyelenggara Jasa Internet Indonesia

Gambar 3. Survei Jumlah Pengguna Internet 2014 dan 2016
Survei Jumlah Pengguna Internet 2014 dan 2016 menunjukan pengguna internet melonjak naik hampir 50\% dari tahun 2014 sampai dengan tahun 2016 yaitu sebanyak 132,7 juta pengguna dari 256,2 juta penduduk atau setengah lebih $(51,8 \%)$ dari total penduduk Indonesia. Besarnya persentase kenaikan angka pengguna internet dalam dua tahun tersebut memberikan jalan bagi biro travel terutama yang baru merintis untuk mempromosikan paket wisata yang mereka tawarkan melalui media online. Rosales (2006:4) menuliskan definisi media online yang merupakan sarana pencerita digital yang menggunakan berbagai teknik dari radio, televisi, dan koran yang disatukan secara interaktif sebagai keunggulan dari internet. Hal tersebut didukung oleh survei perilaku pengguna internet di tahun 2016 dimana sebagian besar orang menggunakan internet untuk melakukan belanja online.

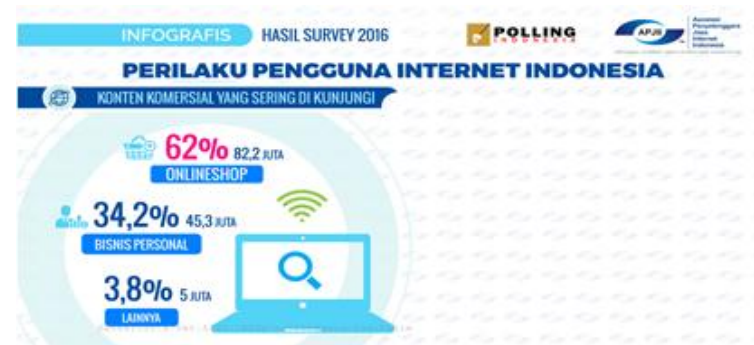

Sumber: Survei Asosiasi Penyelenggara Jasa Internet Indonesia

Gambar 4. Survei Persentase Perilaku Pengguna Internet 2016

Survei Persentase Perilaku Pengguna Internet 2016 menunjukan konten komersial yang paling sering dikunjungi adalah online shop sebesar $62 \%$ atau 82,2 juta konten dan bisnis personal menempati posisi kedua dengan 45,3 juta konten. Survei ini memberikan kesimpulan bahwa media online merupakan media yang efektif sehingga banyak biro travel yang ada saat ini beralih menjalankan biro travel online hanya dengan bermodal website dan akun media sosial. Ananda (2017: 14-25) menyatakan bahwa keberadaan internet menghubungkan setiap orang tanpa ada batas ruang dan waktu sehingga dimanfaatkan oleh pebisnis yang mulai merambah strategi pemasaran melalui media online.

Salah satu promosi yang sering digunakan melalui media online bagi biro travel online saat ini adalah Cause Related Marketing yang merupakan salah satu metode pemasaran dimana sebuah perusahaan bekerjasama dengan badan non-profit untuk melibatkan konsumen berdonasi ketika membeli sebuah produk atau jasa. Tipe promosi ini semakin populer karena konsumen diajak untuk berempati dan ikut mengatasi 
masalah sosial yang ada. Yechiam, Barron, Erev, \& Erez menyatakan "Because of growing public concern over environmental and social issues, corporations have begun to affiliate their products with a range of popular causes, including social and ecological issues" (2002: 320-330).

Perusahaan menyisihkan sebagian dari keuntungan penjualan produk atau jasa untuk membantu mengatasi kasus sosial yang dijadikan objek cause related marketing. Keuntungan yang didapat perusahaan adalah publisitas penyelesaian kasus sosial yang membutuhkan biaya yang besar. Hannantyas, Edy, dan Mawardi (2016) membuktikan dalam cause related marketing terdapat efek positif terhadap brand image. Menurut Ouwersoot dan Tudorica (2001), brand image adalah kumpulan persepsi tentang sebuah merek yang saling berkaitan di dalam pikiran manusia. Salah satu biro travel yang memanfaatkan media online sebagai media pemasaran dengan metode pemasaran cause related marketing adalah ranijourney.com yang menjadi obyek dalam penelitian ini. Ranijourney.com menggunakan metode pemasaran cause related marketing melalui program "Journey For The Hope" yang dilakukan sejak Januari 2016 bekerjasama dengan Lembaga NonProfit Dompet Dhuafa memberikan sebagian keuntungan dari setiap paket wisata yang terjual untuk didonasikan kepada Sekolah Smart Ekselensia yang berada di Parung, Bogor. Pada tahun 2017, ranijourney.com mengganti tujuan pemberian donasi kepada Sekolah Tapal Batas, Pulau Sebatik, Kalimantan Utara dengan alasan salah satu destinasi wisata ranijourney.com yang berada di Kalimantan yaitu Pulau Derawan.
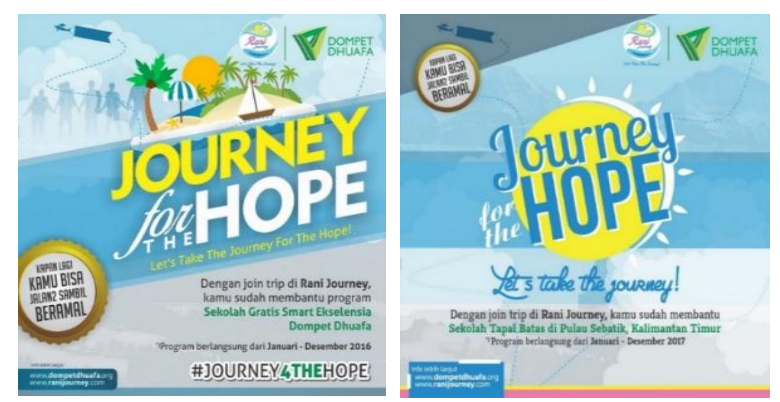

Sumber: Data Primer

Gambar 5. Program "Journey For The Hope" 2016 dan 2017

Kesulitan untuk meraih pendidikan dengan usaha yang sangat beresiko dilakukan oleh anak-anak Indonesia di perbatasan menjadi alasan program "Journey For The Hope" untuk mendonasikan sebagian keuntungan penjualan paket wisata kepada
Sekolah Tapal Batas di Pulau Sebatik, Kalimantan Utara selama tahun 2017. Ross, Stutts, dan Peterson (2011) menuturkan bahwa cause related marketing adalah cara yang tepat dalam mengumpulkan uang untuk mengatasi kasus, menjual produk untuk membantu sebuah kasus dan menunjukan sikap peduli dari perusahaan dan lembaga sosial.

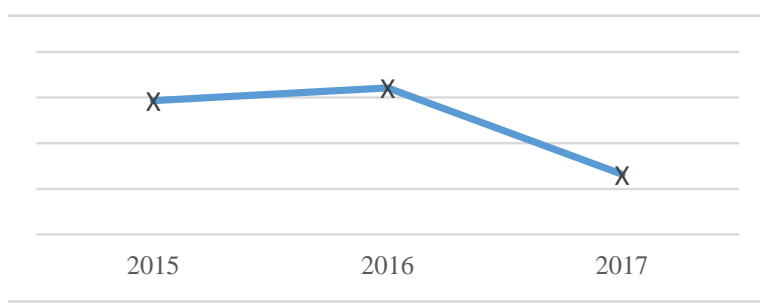

Sumber: Data Primer

Gambar 6. Omset Biro Travel Online ranijourney.com

Program ini memberikan pengaruh positif bagi biro travel online ranijourney.com dengan kenaikan omset dari tahun 2015 ke 2016 sebesar 2\%. Selain itu, program ini juga memiliki pengaruh positif terhadap keputusan pembelian dengan bertambahnya jumlah donasi dari Rp. 40.425.000,- di tahun 2016 naik sebesar 3\% menjadi Rp. 41.690.000,- di tahun 2017. Permasalahan yang terjadi di tahun 2017 adalah penurunan omset ranijourney.com yang lebih besar persentasenya dibandingkan dengan kenaikan omset di tahun pertama yaitu sebesar $12 \%$. Masalah ini menjadi latar belakang dari tujuan penelitian untuk menganalisa program "Journey For The Hope" dan tagline "Kapan Lagi Kamu Bisa Jalan-Jalan Sambil Beramal" dapat mempengaruhi brand trust. Mamahit, Soegoto dan Tumbuan (2015) telah membuktikan bahwa kepercayaan merek mampu mempengaruhi keputusan pembelian konsumen. Semakin tinggi tingkat kepercayaan konsumen maka semakin kuat keputusan pembelian yang dilakukan oleh konsumen yang tentunya akan berpengaruh pada omset perusahaan. Hasil penelitian ini diharapkan memberikan kontribusi terhadap perkembangan ilmu komunikasi pemasaran khususnya pemasaran biro travel online dan memperdalam penggunaan cause related marketing sebagai salah satu cara pemasaran yang dapat memberikan nilai kepada sebuah produk atau jasa.

\section{TINJAUAN PUSTAKA}

Penelitian ini didukung oleh dua teori yang menjelaskan bagaimana sebuah pesan yang disampaikan mampu mempengaruhi pemikiran si penerima pesan sehingga menciptakan opini tertentu.

Social Judgement Theory merupakan teori yang dikemukakan oleh seorang psikolog dari University of 
Oklahoma pada tahun 1961, Muzafer Sherif dan Karl Hovland, menjelaskan tentang cara seseorang menilai sebuah pesan dan mampu mempengaruhi sikap yang menerima pesan tersebut. "Orang yang mendengar sebuah pesan, segera menilai pesan tersebut dan kemudian ditempatkan pada pertimbangan sikap di dalam pikiran" (Griffin, 2006: 207). Perubahan sikap yang terjadi akibat penilaian sosial terhadap sebuah pesan tergantung seberapa penting pesan tersebut bagi seseorang berdasarkan proses internal individu yang terjadi setelah proses persepsi. Littlejohn (2002) membagi perubahan sikap dalam menilai sebuah pesan yang diterima ke dalam tiga bentuk yaitu latitude of acceptance dimana penerima pesan menyetujui pesan yang disampaikan, latitude of rejection penerima pesan tidak menyetujui pesan yang disampaikan, dan latitude of noncommitment dimana penerima pesan tidak berpihak untuk menyetujui pesan atau tidak menyetujui pesan. Menyetujui atau tidak menyetujui pesan tergantung pada keterlibatan emosi individu terhadap pesan yang disampaikan. Jika pesan yang disampaikan memiliki keterlibatan emosi maka penerima pesan akan cenderung menerima pesan tersebut, sebaliknya jika pesan yang disampaikan tidak memiliki keterlibatan emosi maka penerima pesan cenderung untuk menolak pesan tersebut. Pada bentuk sikap ketidakberpihakan, si penerima pesan cenderung untuk tidak peduli dengan pesan yang tidak memiliki keterlibatan emosi. Social judgement theory mendukung penelitian ini dimana adanya pesan yang disampaikan dalam program "Journey For The Hope" ranijourney.com untuk mengajak konsumen ikut berdonasi mengatasi kasus sosial keterbatasan mendapat pendidikan yang layak di Indonesia melalui pembelian paket wisata. Alasan tersebut diangkat untuk mendapatkan keterlibatan emosi bagi orang yang menerima pesan sehingga menimbulkan persepsi positif dan membentuk sikap positif yang akan berpengaruh kepada brand image dan brand trust ranijourney.com.

Elaboration Likelihood Theory dikembangkan oleh Richard Petty dan John Cacioppo pada tahun 1980 menjelaskan tentang pengambilan keputusan dari pesan yang disampaikan tergantung pada proses penyampaian pesan tersebut. Teori ini menjelaskan bahwa pesan yang disampaikan akan diterima secara kritis oleh penerima pesan, namun dalam situasi tertentu pesan akan diterima tanpa mempertimbangakan alasan yang mendasari isi pesan tersebut (Griffin, 2006). Menurut Widiastuti (2017) Elaboration Likelihood Model digunakan sebagai teori dasar untuk menilai kualitas informasi terhadap kepercayaan pengguna sosial media, maka kualitas argumen dan kredibilitas sumber memiliki kesan positif dalam pembentukan kesan. Elaboration Likelihood Theory mendukung penelitian ini dimana pesan positif yang disampaikan oleh program "Journey For The Hope" dalam mengajak konsumen untuk berdonasi melalui pembelian paket wisata mampu membentuk kesan yang positif.

\section{METODE PENELITIAN}

Peneliti menggunakan metode penelitian kuantitatif agar hasil penelitian dapat digeneralisasikan dimana instrumen pengumpulan datanya menggunakan kuesioner. Fenomena yang akan diteliti dalam penelitian ini adalah "Pengaruh Cause Related Marketing Dan Brand Image Terhadap Brand Trust Pada Biro Travel Online". Variabel independen (X) adalah cause related marketing, variabel intervening (Z) adalah brand image dan variable independen (Y) adalah brand trust.

Populasi dalam penelitian ini adalah peserta yang telah berpartisipasi dalam program "Journey For the Hope" ranijourney.com di tahun 2017 yaitu sebanyak 8.338 peserta diambil dari total donasi di tahun 2017 yaitu sebesar Rp. 41.690.000,- dibagi dengan nominal donasi per peserta yang berpartisipasi yaitu $\mathrm{Rp}$. 5.000,-. Peneliti mengambil sampel dengan menggunakan teknik sampling probabilita dimana semua peserta memiliki peluang untuk dijadikan sampel. Salah satu jenis teknik sampling probabilita yang digunakan adalah teknik random sampling dimana sampel dipilih secara acak. Dalam penelitian ini maka ukuran sampel yang digunakan dengan perhitungan rumus Slovin, yaitu:

$$
\mathrm{n}=\frac{8.338}{1+8.338(0,1)^{2}}=\frac{8.338}{1+83,38}=\frac{8.338}{84,38}=98,81
$$

Dari perhitungan di atas menghasilkan jumlah sampel sebanyak 99 peserta trip ranijourney.com yang pernah berpartisipasi dalam program "Journey For The Hope" selama tahun 2017.

Teknik analisis data yang digunakan dalam penelitian ini adalah teknik analisis data inferensial yang terbagi menjadi beberapa teknik analisis, salah satu yang digunakan oleh peneliti dalam penelitian ini adalah analisis korelasi multivariate. Hubungan dua variabel dikenal dengan istilah bivariate correlation, sedangkan hubungan antar lebih dari dua variabel disebut multivariate correlation (Muhidin dan Abdurahman, 2007). Teknik analisis korelasi ini dilanjutkan dengan analisis regresi yang bertujuan untuk melihat pengaruh variabel independen terhadap 
variabel dependen. Penelitian ini juga digunakan untuk mengetahui hubungan sebab akibat antara variabel independen terhadap variabel dependen melalui variabel perantara sehingga tenik analisis data yang dilakukan selanjutnya adalah teknik analisis jalur.

Peneliti akan mengolah data menggunakan bantuan program SPSS 24. For Windows dengan rumus statistik Pearson Product Moment setelah data terkumpul. Pearson Product Moment digunakan oleh peneliti dikarenakan variabel-variabel dalam penelitian ini memiliki tingkat pengukuran interval. Menurut Malhotra (2009), skala interval adalah skala yang menggunakan angka untuk memeringkat obyek sedemikian rupa sehingga jarak setara secara numerik mewakili jarak setara karakteristik yang sedang diukur. Terkait dengan skala pengukuran, peneliti menggunakan skala Likert sebagai skala pengukuran yang digunakan untuk mengukur sikap. Skala Likert digunakan untuk mengukur sikap, pendapat dan persepsi seseorang tentang fenomena sosial (Darmawan, 2016).

\section{ANALISA DATA DAN HASIL}

\subsection{Analisis Korelasi}

Tabel 1. Uji Korelasi Variabel X (Cause Related Marketing), Variabel Z (Brand Image dan Variabel Y (Brand Trust)

\begin{tabular}{llccc}
\hline & & CRM & BI & BT \\
\hline CRM & Pearson Correlation & & $.668^{* *}$ & $.695^{* *}$ \\
& Sig. (2-tailed) & & .000 & .000 \\
BI & Pearson Correlation & $.668^{* *}$ & & $.868^{* *}$ \\
& Sig. (2-tailed) & .000 & & .000 \\
BT & Pearson Correlation & $.695^{* *}$ & $.868^{* *}$ & \\
& Sig. (2-tailed) & .000 & .000 & \\
\hline
\end{tabular}

Hasil uji korelasi tiga variable dari tabel 1 dapat diartikan bahwa variabel $X$ (cause related marketing) memiliki hubungan dengan variabel $\mathrm{Z}$ (brand image) melalui hasil signifikansi (2-tailed) sebesar 0,000 karena nilai tersebut lebih kecil dari nilai signifikansi 0,050. Korelasi variabel X (cause related marketing) dengan variabel $\mathrm{Z}$ (brand image) memiliki nilai koefisien korelasi sebesar 0,668 dimana nilai tersebut menunjukan adanya hubungan positif antara variabel $\mathrm{X}$ dan $\mathrm{Z}$ dengan tingkat korelasi sedang. Variabel $\mathrm{X}$ (cause related marketing) memiliki hubungan dengan variabel Y (brand trust) melalui hasil signifikansi (2tailed) sebesar 0,000 karena nilai tersebut lebih kecil dari nilai signifikansi 0,050 . Korelasi variabel $X$ (cause related marketing) dengan variabel Y (brand trust) memiliki nilai koefisien korelasi sebesar 0,695 dimana nilai tersebut menunjukan adanya hubungan positif antara variabel $\mathrm{X}$ dan $\mathrm{Y}$ dengan tingkat korelasi sedang. Variabel Z (brand image) memiliki hubungan dengan variabel Y (brand trust) melalui hasil signifikansi (2-tailed) sebesar 0,000 karena nilai tersebut lebih kecil dari nilai signifikansi 0,050. Korelasi variabel Z (brand image) dengan variabel $\mathrm{Y}$ (brand trust) memiliki nilai koefisien korelasi sebesar 0,868 dimana nilai tersebut menunjukan adanya hubungan positif antara variabel $\mathrm{Z}$ dan $\mathrm{Y}$ dengan tingkat korelasi sangat kuat.

\subsection{Analisis Regresi}

Tabel 2. Nilai Signifikansi

\begin{tabular}{cl}
\hline Variabel & Sig. \\
\hline CRM & $.000^{\mathrm{b}}$ \\
BI & $.000^{\mathrm{b}}$ \\
BT & $.000^{\mathrm{b}}$ \\
\hline
\end{tabular}

Sumber: Data Primer 2018

Tabel 2 menjelaskan ada pengaruh yang signifikan antara variabel $X$ (cause related marketing) terhadap variabel $\mathrm{Z}$ (brand image), variabel $\mathrm{X}$ (cause related marketing) terhadap variabel Y (brand trust) dan variabel Z (brand image) terhadap variabel Y (brand trust) yang dapat dilihat dari nilai signifikansi sebesar 0,000 . Nilai-nilai tersebut lebih kecil dari probabilitas $0,050(0,000<0,050)$ sehingga dapat disimpulkan bahwa persamaan regresi variabel $X$ secara signifikan mempengaruhi variabel $Z$, variabel $X$ secara signifikan mempengaruhi variabel $Y$ dan variabel $Z$ secara signifikan mempengaruhi variabel Y.

\subsection{Analisis Regresi Linier Berganda}

Tabel 3. Uji Regresi Variabel X dan Variabel Z Terhadap Variabel Y

\begin{tabular}{cl}
\hline R Square & Sig. \\
\hline .778 & $.000^{\mathrm{b}}$ \\
\hline
\end{tabular}

Sumber: Data Primer 2018

Tabel 3 menjelaskan apakah ada pengaruh yang signifikan antara variabel $X$ (cause related marketing) dan variabel $\mathrm{Z}$ (brand image) terhadap variabel $\mathrm{Y}$ (brand trust) yang dapat dilihat dari nilai signifikansi sebesar 0,000 . Nilai tersebut lebih kecil dari probabilitas $0,050(0,000<0,050)$ sehingga dapat disimpulkan bahwa persamaan regresi variabel $\mathrm{X}$ dan $\mathrm{Z}$ secara signifikan mempengaruhi variabel Y.

\subsection{Analisis Jalur}

Analisis jalur dalam penelitian ini membutuhkan nilai koefisien residu untuk menemukan nilai koefisien jalur dengan perhitungan sebagai berikut: 
$\rho Z \varepsilon_{1}=\sqrt{1-R^{2}}=\sqrt{1-0.778}=0,471$

Hasil dari keseluruhan perhitungan dalam analisis jalur dapat disimpulkan melalui tabel 4.

Tabel 4. Tabel Coefficients

\begin{tabular}{cccc}
\hline Variabel & $\begin{array}{c}\text { Koefisien Jalur } \\
\text { Langsung }\end{array}$ & $\begin{array}{c}\text { Koefisien Jalur } \\
\text { Tidak Langsung }\end{array}$ & Total \\
\hline $\mathrm{X}-\mathrm{Z}$ & 0,668 & & 0,668 \\
$\mathrm{X}-\mathrm{Y}$ & 0,695 & $0,695 \times 0,471$ & 0,315 \\
$\mathrm{Z}-\mathrm{Y}$ & 0,868 & & 0,868 \\
$\varepsilon_{1}$ & 0,471 & & 0,744 \\
\hline Sumber: & &
\end{tabular}

Sumber: Data Primer 2018

Tabel 4 menunjukan bahwa koefisien jalur langsung variabel $\mathrm{X}$ (cause related marketing) terhadap variabel Y (brand trust) memiliki nilai yang lebih tinggi dibanding nilai koefisien jalur tidak langsung melalui variabel $\mathrm{Z}$ (brand image). Koefisien jalur variabel Z (brand image) terhadap variabel Y (brand trust) memiliki nilai paling tinggi, sedangkan koefisien jalur variabel $\mathrm{X}$ (cause related marketing) terhadap variabel $\mathrm{Z}$ (brand image) memiliki nilai yang paling rendah.

\section{PEMBAHASAN}

\subsection{Cause Related Marketing}

Tabel 5. Mean Dimensi Variabel X (Cause Related Marketing)

\begin{tabular}{cc}
\hline Dimensi & Mean \\
\hline Elemen Kognitif & 4,6 \\
Elemen Afektif & 4,8 \\
Elemen Intensional & 4,5 \\
\hline
\end{tabular}

Sumber: Data Primer 2018

Tabel 5 menunjukan bahwa dimensi Elemen Afektif memiliki mean paling tinggi diantara dimensi yang lain yang didukung oleh jawaban responden dimana semua responden setuju pada pernyataaan-pernyataan yang menjelaskan tentang indikator Perasaan dan 99\% responden setuju pada pernyataaan-pernyataan dalam indikator Emosi. Hasil tersebut dapat diartikan bahwa kegiatan cause related marketing pada program "Journey For The Hope" ranijourney.com mampu mempengaruhi sikap responden melalui elemen afektif.

Elemen kognitif menunjukan bahwa hampir semua (98\%) responden berhasil menerima promosi program "Journey For The Hope" dan 89\% responden mengetahui kegiatan tersebut dilakukan atas kerjasama ranijourney.com dan Dompet Dhuafa. Sebagian besar responden (94\%) mengetahui bahwa Dompet
Dhuafa merupakan lembaga nirlaba yang membantu masalah kemanusian sehingga pemilihan lembaga untuk bekerjasama dengan ranijourney.com dalam program "Journey For The Hope" sudah tepat. Sebanyak $90 \%$ responden juga yakin bahwa ranijourney.com telah menyalurkan donasi kepada Sekolah Tapal Batas, Kalimantan Utara.

Walaupun Elemen Intensional memiliki mean dimensi paling rendah, namun pada pernyataan dalam indikator tindakan, sebanyak $91 \%$ responden setuju mengikuti trip ranijourney.com karena ingin membantu sesame dan $88 \%$ responden mengajak temanteman mereka untuk mengikuti trip ranijourney.com agar dapat berpartisipasi membantu Sekolah Tapal Batas. Keterlibatan emosi seseorang terhadap suatu kasus yang diangkat melalui kegiatan cause related marketing dalam program "Journey For The Hope" ranijourney.com mampu menggiring responden untuk mengambil keputusan membeli paket wisata yang ditawarkan. Sesuai dengan Social Judgement Theory yang menjelaskan bahwa sebuah pesan mampu mempengaruhi sikap penerima pesan mendukung hasil jawaban dari pernyataan ini.

\subsection{Brand Image}

Tabel 6. Mean Dimensi Variabel Z (Brand Image)

\begin{tabular}{cc}
\hline Dimensi & Mean \\
\hline Kekuatan Asosiasi Merek & 4,58 \\
Keuntungan Asosiasi Merek & 4,44 \\
Keunikan Asosiasi Merek & 4,53 \\
\hline
\end{tabular}

Sumber: Data Primer 2018

Tabel 6 menunjukan bahwa dimensi Kekuatan Asosiasi Merek memiliki mean paling tinggi didukung dengan jawaban kuesioner dimana hampir semua (99\%) responden setuju bahwa ranijourney.com adalah biro travel online yang dapat dipercaya. Hasil tersebut menjelaskan bahwa ranijourney.com merupakan brand yang mampu menyampaikan pesan yang kuat ke dalam benak responden sehingga menjadi bagian dari brand image. Keller menyatakan "Creating a positive brand image takes marketing program that link strong, favourable, and unique associations to the brand in memory" (2008: 56). Pernyataan selanjutnya menunjukan $95 \%$ responden setuju bahwa ranijourney.com menawarkan trip dengan harga yang terjangkau. Kegiatan wisata dengan kapasitas peserta trip yang banyak (20 - 30 orang) dapat meminimalisir biaya akomodasi seperti penginapan dan transportasi sehingga harga paket wisata yang ditawarkan ranijourney.com cukup terjangkau. 
Pada dimensi Keuntungan Asosiasi Merek, 96\% responden percaya bahwa ranijourney.com menyediakan akomodasi yang dibutuhkan untuk perjalanan wisata dan $97 \%$ responden juga percaya bahwa ranijourney.com tidak hanya mencari keuntungan pribadi tetapi juga peduli dengan masalah pendidikan di Indonesia. Hasil ini membuktikan bahwa kegiatan cause related marketing pada program "Journey For The Hope" mampu membentuk brand image ranijourney.com sebagai biro travel online yang peduli dengan kasus sosial di Indonesia, terutama pendidikan. Hasil tersebut didukung oleh Elaboration Likelihood Theory yang menjelaskan tentang proses persepsi dari sebuah pesan yang diterima sebelum terbentuk perubahan sikap.

Dimensi Keunikan Asosiasi Merek menghasilkan 96\% jawaban setuju bahwa melalui trip ranijourney.com responden dapat mengunjungi destinasi wisata menarik di Indonesia. 93\% responden juga setuju bahwa trip gabungan ranijourney.com memberikan kesempatan kepada peserta yang tidak memiliki teman perjalanan untuk bergabung dan berkenalan dengan teman baru selama berwisata.

\subsection{Brand Trust}

Tabel 7. Mean Dimensi Variabel Y (Brand Trust)

\begin{tabular}{cc}
\hline Dimensi & Mean \\
\hline Brand Characteristic & 4,42 \\
Company Characteristic & 4,46 \\
Consumer-Brand Characteristic & 4,45 \\
\hline
\end{tabular}

Sumber: Data Primer 2018

Tabel 7 menunjukan bahwa dimensi Company Characteristic memiliki mean paling tinggi didukung dengan $92 \%$ responden percaya dengan perusahaan yang mengelola brand ranijourney.com dan $91 \%$ responden yakin bahwa ranijourney.com menjalankan trip ke berbagai destinasi wisata yang ditawarkan. Sebanyak 94\% responden setuju bahwa ranijourney.com merupakan biro travel online yang memiliki jadwal perjalanan setiap minggu karena jadwal trip selalu di-update melalui media sosial Instagram, Facebook, Fanpage dan Twitter dan juga 95\% responden setuju bahwa ranijourney.com memiliki tour guide yang ramah dan menyenangkan. Pada indikator Tujuan Perusahaan, 96\% responden setuju bahwa ranijourney.com bertujuan untuk menyediakan akomodasi kepada peserta untuk melihat keindahan alam Indonesia dengan biaya yang terjangkau. Selanjutnya, 94\% responden setuju bahwa ranijourney.com tidak hanya menawarkan paket wisata tetapi juga mengajak peserta untuk ikut membantu sekolah di daerah terpencil Indonesia melalui kegiatan cause related marketing dalam program "Journey For The Hope". Besarnya persentase setuju dalam indikator ini didukung oleh Elaboration Likelihood Theory dimana proses penyampaian pesan yang positif akan menciptakan kesan yang positif dalam benak konsumen, salah satunya kepercayaan terhadap merek dalam melakukan sesuatu yang positif.

Pada dimensi Brand Characteristic, sebanyak $87 \%$ responden setuju bahwa ranijourney.com tidak pernah terlibat dalam kasus penipuan dan $91 \%$ responden setuju bahwa ranijourney.com memiliki pilihan destinasi wisata yang menarik. Pada indikator Kompetensi Brand, sekitar 96\% responden setuju bahwa ranijourney.com melayani peserta trip sesuai dengan akomodasi yang disediakan dan akomodasi tersebut sesuai dengan harga yang ditawarkan.

Dimensi Consumer-Brand Characteristis menunjukkan bahwa $89 \%$ responden merasa senang dengan akomodasi ang disediakan oleh ranijourney.com dan tentunya 95\% responden menyukai konsep ranijourney.com yang mengajak peserta untuk ikut berdonasi bagi pendidikan Indonesia. Kepuasan juga ditunjukan dalam dimensi ini dimana $90 \%$ responden setuju bahwa pelayanan tour guide ranijourney.com memuaskan selama trip berlangsung. Persentase yang lebih tinggi dirasakan oleh $95 \%$ responden yang merasa puas mengikuti trip ranijourney.com karena mendapat pengalaman yang berkesan. Pengalaman yang berkesan ini didukung oleh destinasi dan kegiatan wisata yang menarik serta konsep trip gabungan yang membuat peserta trip memilki pertemanan baru.

Tabel 8. Perbandingan Nilai Persentase Hasil Pernyataan

\begin{tabular}{cccc}
\hline Variabel & Setuju & Ragu-Ragu & Tidak Setuju \\
\hline X & $94,6 \%$ & $4,8 \%$ & $0,6 \%$ \\
Y & $94,6 \%$ & $5,1 \%$ & $0,3 \%$ \\
Z & $92,9 \%$ & $6,9 \%$ & $0,2 \%$ \\
\hline
\end{tabular}

Sumber: Data Primer 2018

Tabel 8 menunjukan bahwa variabel X (cause related marketing) memiliki persentase tidak setuju yang paling banyak diantara variabel lainnya. Hasil tersebut dapat mendukung hasil dari koefisien jalur variabel $\mathrm{X}$ (cause related marketing) terhadap variabel $\mathrm{Y}$ (brand trust) melalui $\mathrm{Z}$ (brand image) dengan nilai yang lebih rendah dibandingkan koefisien jalur langsung variabel $\mathrm{X}$ (cause related marketing) terhadap variabel Y (brand trust). Persentase tidak setuju pada variabel X (cause related marketing) tersebut dua kali lipat dibanding variabel Y (brand trust) dan tiga kali 
lipat dibanding variabel $\mathrm{Z}$ (brand image). Tingginya nilai ketidaksetujuan ini terletak pada pernyataan "Saya mengetahui ranijourney.com bekerja sama dengan Dompet Dhuafa untuk membantu Sekolah Tapal Batas, Kalimantan Utara" dengan angka ketidaksetujuan yang paling tinggi yaitu $0,34 \%$. Hasil tersebut dapat terjadi karena media promosi yang digunakan Dompet Dhuafa dalam program ini kurang maksimal dan materi promosi yang kurang menunjukan peran Dompet Dhuafa.

\section{KESIMPULAN}

Berdasarkan penelitian yang telah dilakukan, maka diperoleh hasil bahwa Terdapat pengaruh cause related marketing terhadap brand image, cause related marketing terhadap brand trust, brand image terhadap brand trust dan cause related marketing terhadap brand trust melalui brand image. Hasil tersebut membuktikan bahwa program "Journey For The Hope" dan tagline "Kapan Lagi Kamu Bisa Jalan-Jalan Sambil Beramal" mampu mempengaruhi brand trust biro travel online ranijourney.com.

\section{DAFTAR PUSTAKA}

Ananda, L., D. (2017). Dinamika trust pada pemasaran online di media sosial. Jurnal Komunikasi Indonesia, 5(1), 14-25.

Darmawan, D. (2016). Metodologi penelitian kuantitatif. Bandung: Remaja Rosdakarya.

Data kunjungan wisatawan mencanegara bulan oktober 2017. Diakses pada Oktober 20, 2017, dari website Kementerian Pariwisata: ttp://www. kemenpar.go.id/image/contenttransaction/3504.png

Griffin, E. M. (2006). A first look at communication theory. Singapore: The McGraw Hill Companies.

Hannantyas, A. A., Yulianto, E., \& Mawardi, M. K. (2016). The role of cause-related marketing on multinational corporate reputation, brand image, and purchase intention in indonesia and thailand (study case on the body shop against animal testing campaign). Jurnal Administrasi Bisnis, 33(2), 11-17.

Jumlah pengguna internet tahun 2014 dan 2016. Asosiasi Penyelenggara Jasa Internet Indonesia: survei@apjii.co.id.

Littlejohn, S. W. (2002). Theories of human communication. USA: Thomson Learning.

Malhotra, N. K. (2009). Riset pemasaran. Jakarta: Indeks.

Mamahit, P., Soegoto, S. S., Tumbuan, W. A. (2015). Pengaruh brand image, brand trust, dan kualitas produk terhadap keputusan pembelian mobil toyota all new yaris pad apt. hasjrat abadi manado. Jurnal Berkala Ilmiah Efisiensi, 15(5), 777-787.

Muhidin, S., \& Abdurahman, M. (2007). Analisis korelasi, regresi dan jalur dalam penelitian. Bandung: Pustaka Setia.

Ouwersloot, H., \& Tudorica, A. (2001). Brand personality creation through advertising dalam Maxx Working Paper 2001-01. February 2nd 2001.

Ranking devisa pariwisata terhadap 5 ekspor barang terbesar tahun 2012-2015. Diakses pada Desember 25, 2017, dari website Kementerian Pariwisata: http://www.kemenpar.go.id/userfiles/devisa2011-2015.pdf

Rosales, R., G. (2006). The elements of online journalism. USA: iUniverse.

Ross, J. K., Stutts, M. A., \& Patterson, L. (2011). Tactical consideration for the effective use of cause-related marketing. The Journal of Applied Business Reasearch, 7(2), 58-65.

Widiastuti, T. (2017). Analisis elaboration likelihood model dalam pembentukan personal branding ridwan kamil di twitter. Jurnal ASPIKOM, 3(3), 588-603.

Yechiam, E., Barron, G., Erev, I., \& Erez, M. (2002). On the robustness and the direction of the effect of cause-related marketing. Journal of Consumer Behaviour, 2(4), 320-330. 